\title{
Properties of sand concrete with recycled tyre polymer fibers
}

\author{
Oksana Larsen", Viktoria Shvetsova, Ekaterina Patsenko, and Artyom Polozov
}

Moscow State University of Civil Engineering, Yaroslavskoe shosse, 26, Moscow, 129337, Russia

\begin{abstract}
Disposal of tyre waste is a major environmental problem in all over of the world. It has been estimated that more than 1.5 billion tyres are produced annually and almost one million end their service life. More than $50 \%$ of them are accumulated on landfills. The tyre fiber can be added to the concrete mixture to improve not only the strength properties, but also the crack resistance of the composition. The use of recycled tire polymer fibers as reinforcement component is a perspective view on the development of dispersed concrete technology. In this research the main characteristics of the fiber and the technological characteristics of the concrete mixture are presented. The effect of the polymer fiber on strength and performance properties of sand concrete are shown. It was found that the optimal dosage of fiber is $1 \mathrm{~kg} / \mathrm{m}^{3}$, the adding of the fiber reduces at the range $3.6 \%$ of slump of the concrete mixture. It was found that each 10 $\mathrm{kg} / \mathrm{m}^{3}$ of recycled polymer fiber reduce the density of samples by $4 \%$. The addition of such amount of the polymer fiber reduces the compressive strength. The addition of $1 \mathrm{~kg} / \mathrm{m}^{3}$ has the significant effect on the reduction of the compressive and flexural concrete strength with class B15, while the same characteristics of concrete with class B30 are higher. The results of this research allow to conclude that such fiber is suitable to use in concrete with class B30 and lower.
\end{abstract}

\section{Introduction}

The global environmental situation is drawing more and more attention. The recycling of expired tyres is a global environmental problem. Many scientists have started exploring the possibility of using wastes in building constructions and constructional materials.

The vehicle tyre consists of a tyre frame, tread belt layers, a tyre tread, a side and a side wall. The belt ply is located between the tyre frame and the tyre tread. It consists of cord plies and serves to improve the connection of the tyre frame to the tyre tread and to cushion impact force. It also improves the resistance of the tyre frame to mechanical damage. The cord threads of the belt ply are arranged diagonally regardless of the tyre construction. Cords can be textile, fiberglass, or metal. Textile or fiberglass cords are used in different passenger cars, whereas metal cords are used in lorries.

\footnotetext{
* Corresponding author: larsen.oksana@mail.ru
} 
Nowadays the use of recycled tyres and their components (reinforcing materials, rubber crumb, etc.) has found application in the production of concrete. Fiber concrete is concrete, which is reinforced with dispersed fibers [1]. Steel, glass, basalt, carbon, natural, synthetic fibers can be used as dispersed reinforcement. The efficiency of fibers in fiber-reinforced concrete structures can be characterized by concrete modulus of elasticity, the value of which indicates tension set of the fiber. Therefore, the fibers can be divided into low modulus (synthetic) and high modulus (steel, glass, etc.). The reinforcement of the lowmodular fibres increases the crack resistance and modulus of resilience, whereas the reinforcement of the high-modulus fibers is expected to improve strength characteristics [2]. Tyre cord fibers are classified as low-modular and they are added to the concrete mixture to improve resistance and to have a positive impact on deformation at an early age $[3]$.

It was established [3] the impact of purified and crude tyre cord on strength, elastic modulus, shrinkage and cold endurance in a saline solution of fiber reinforced concrete.

For the first time, the method of purification of synthetic fibers from metal and textile inclusions as well as from rubber crumbs of different fractions is proposed by [3] in Figure 1.

a)

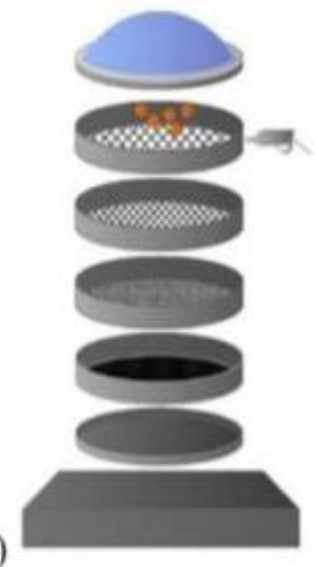

b)

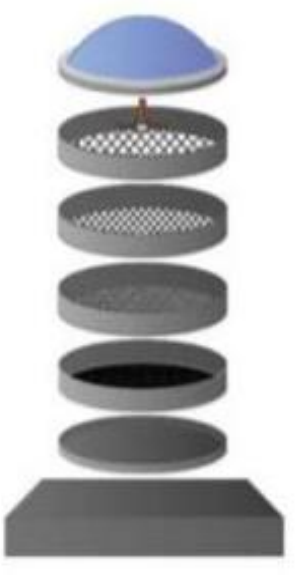

Fig. 1. Cleaning procedure of RTPF: a) $1^{\text {st }}$ stage, b) $2^{\text {nd }}$ stage [3].

Crude cord is placed together with the rubber balls in an upper sieve of structure, which is consisted of 4 sieves with holes of $0.25 ; 0.71 ; 2$ and $4 \mathrm{~mm}$. The structure is installed on a flow table and shaken. The process takes place in 2 stages. Stage 2 differs from stage 1 by the presence of pneumatic equipment, which creates an airstream, that prevents the fiber from settling together with the rubber crumbs on the bottom of the installation. According to the research, crude cord consists of $15 \%$ pure fiber, $20 \%$ fiber contaminated with fine fraction of rubber crumb and $65 \%$ rubber crumb. Crude cord is usually heavily contaminated with residual rubber particles that can influence the concrete properties [4].

Authors [5] created the method with structure consisting of a wooden frame with nylon threads attached to it, a wooden box and a blow machine. The process of integration begins with placing some of the fibers over the net, then the strings are manually energized and the vibration of the string unravels the fibers, as it is depicted in Figure 2. A storage bunker for collecting fibers is located under the frame. 


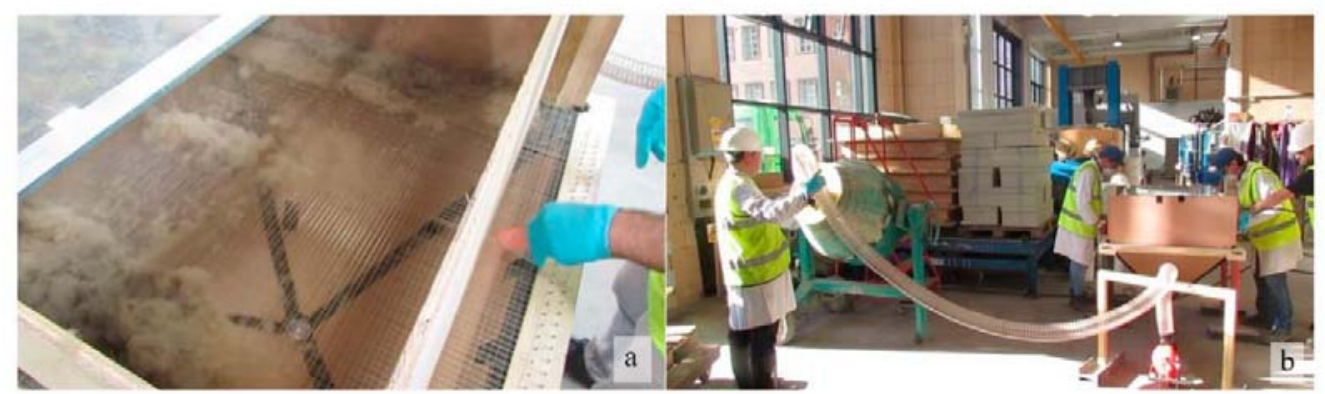

Fig. 2. Fiber cleaning equipment: a) strings being manually excited; b) fibers being integrated into the concrete mix [4].

The authors [6] concluded that the use of fibers has a positive effect on shrinkage deformations. In research [7] was stated that concrete with fibers has shrinkage value from 0.0140 to $0.0061 \mathrm{~mm} / \mathrm{m}$ which is less than the concrete shrinkage without fiber and is equal to $0.0596 \mathrm{~mm} / \mathrm{m}$.

The influence of polymer fibers on mechanical properties of concrete is considered in $[3,5]$. It was stated [8] that the addition of mixed polymer fibers in amounts of 5, 10 and 15 $\mathrm{kg} / \mathrm{m}^{3}$ leads to $4.9 ; 9.3$ and $17.8 \%$ reduction of compressive strength in 48 hours. The addition of purified fibers up to $5 \mathrm{~kg} / \mathrm{m}^{3}$ results in a $5 \%$ reduction of compressive strength. M.Chen, et al. [9] confirmed that the addition polymer fibers up to $5 \mathrm{~kg} / \mathrm{m}^{3}\left(4.8 \mathrm{~kg} / \mathrm{m}^{3}\right)$ does not significantly reduce the compressive strength, whereas with an amount of more than $5 \mathrm{~kg} / \mathrm{m} 3\left(9.6 \mathrm{~kg} / \mathrm{m}^{3}\right)$ the compressive strength is $23.0 \%$ in 7 days, and it is $17.7 \%$ at the age of 28 days.

C. Meng et al. $[10,11]$ proved that with the continuous inclusion of fibers in an amount of 4.8 and $9.6 \mathrm{~kg} / \mathrm{m} 3$, bending strength decreased by $2.1 \%$ and by $3.6 \%$. However, compared with the reference mixtures, the bending strength of the samples with recycled polymer fibers increased by $3.6 \%, 9.6 \%, 7.3 \%$ and $5.6 \%$. They also concluded that a poor distribution of fibers within the samples affects the decrease in bending strength $[12,13]$. The research of A. Baricevic et al [14] proved otherwise. They claimed that if less fiber is added to wet-sprayed concrete, bending strength decreases, and if more fiber is added, it increases.

In this research, a new cleaning method of recycled tire polymer fiber is proposed, and the effect of fiber on strength characteristics of sand concrete mixture is studied.

\section{Materials and methods}

The Portland Cement CEM II/A-S(S1-1) $42,5 \mathrm{~N}$ as a binder was used. The main characteristics are presented in Table 1.

Table 1. The characteristics of Portland Cement.

\begin{tabular}{|c|c|c|c|c|c|c|c|c|c|c|c|c|}
\hline \multicolumn{13}{|c|}{ Mineralogical composition of the clinker (\%) } \\
\hline \multicolumn{3}{|c|}{$\mathrm{C}_{3} \mathrm{~S}$} & \multicolumn{4}{|c|}{$\mathrm{C}_{2} \mathrm{~S}$} & \multicolumn{3}{|c|}{$\mathrm{C}_{3} \mathrm{~A}$} & \multicolumn{3}{|c|}{$\mathrm{C}_{4} \mathrm{AF}$} \\
\hline \multicolumn{3}{|c|}{70,1} & \multicolumn{3}{|c|}{7,4} & & \multicolumn{3}{|c|}{4,8} & \multicolumn{3}{|c|}{12,1} \\
\hline \multicolumn{13}{|c|}{ Chemical composition of cement $(\%)$} \\
\hline 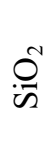 & 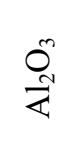 & ర్లు & 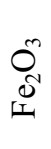 & $\sum_{i}^{0}$ & $\overbrace{\mathscr{C}}^{N}$ & $0^{n}$ & ○ & $\begin{array}{l}0 \\
\underset{\mathbb{Z}}{Z}\end{array}$ & $\underset{\widetilde{N}}{0}$ & $\begin{array}{l}0 \\
\mathbb{Z} \\
Z\end{array}$ & 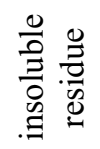 & $\bar{U}$ \\
\hline
\end{tabular}




\begin{tabular}{|l|c|c|c|c|c|c|c|c|c|c|c|c|}
\hline 21,0 & 5,2 & 58,0 & 2,8 & 5,0 & 0,3 & 0,1 & 2,7 & 0,1 & 0,5 & 0,4 & 0,0 & 0,01 \\
\hline
\end{tabular}

Quartz sand was used as fine aggregate according to Russian standard GOST 87362014. Superplasticizer Sika ViscoCrete E55 (SVC E55) was used in amount of $1 \%$ by weight of cement.

The initial fiber mixture consisted with polymer fiber, different fractions of rubber crumbs and metal fibers. Figure 3 shows the different types of fiber mixture (FM): FM1, FM2, FM3.

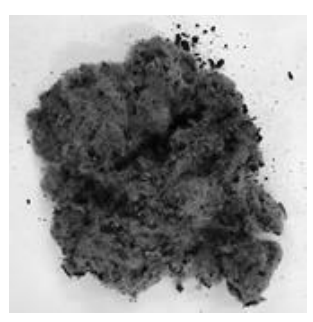

FM1

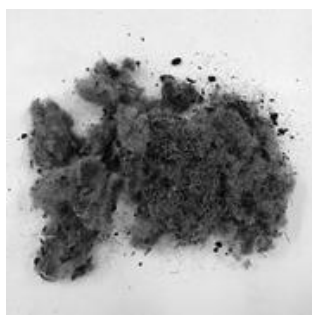

FM2

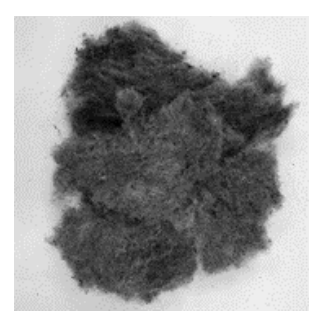

FM3

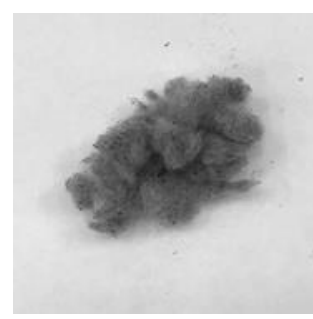

FM1-1

Fig. 3. Different types of the tyre cord mixture.

The FM1 mixture was a combination of rubber crumbs of different fractions, polymer fiber and metal fibers. A mixture of FM2 type is a knocked down lump of metal and polymer fibers, rubber crumb is almost absent. A mixture of type FM3 is represented by polymer fiber with rubber dust, rubber crumb and metal fiber are almost absent.

The dosage of the components of the fine-grained concrete mixture is presented in Table 2.

Table 2. Mix propotion of sand concrete.

\begin{tabular}{|c|c|c|c|c|c|c|}
\hline \multirow{2}{*}{$\begin{array}{c}\text { Series of } \\
\text { the } \\
\text { samples }\end{array}$} & \multicolumn{6}{|c|}{ The components consumption $\left(\mathrm{kg} / \mathrm{m}^{3}\right)$} \\
\cline { 2 - 7 } & Cement & Water & W/C & Sand & Fiber & SVC E55 \\
\hline $15-0$ & 473,1 & 297,3 & 0,63 & 1419,3 & - & 4,73 \\
\hline $15 \mathrm{~F}-1$ & 473,1 & 297,3 & 0,63 & 1419,3 & 1 & 4,73 \\
\hline $15 \mathrm{~F}-10$ & 473,1 & 297,3 & 0,63 & 1419,3 & 10 & 4,73 \\
\hline $30-0$ & 510,7 & 241,4 & 0,47 & 1532,2 & - & 5,1 \\
\hline $30 \mathrm{~F}-1$ & 510,7 & 241,4 & 0,47 & 1532,2 & 1 & 5,1 \\
\hline $30 \mathrm{~F}-10$ & 510,7 & 241,4 & 0,47 & 1532,2 & 10 & 5,1 \\
\hline 45 & 536,5 & 203,2 & 0,38 & 1609,4 & - & 5,4 \\
\hline $45 \mathrm{~F}-10$ & 536,5 & 203,2 & 0,38 & 1609,4 & 10 & 5,4 \\
\hline
\end{tabular}

In this research the method of fiber mixture cleaning with the use of screen with metal sieves was used in Figure 4. This method turned out to be quite lengthy and inefficient [15]. Therefore, subsequently, instead of using sieves with metal threads, was used "sieve" with polyamide threads, which reduces/cuts the time of cleaning the fiber from the largest rubber particles (Fig. 5). 


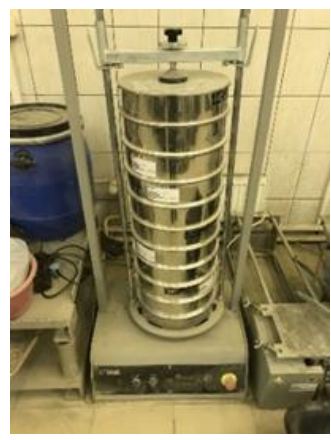

Fig. 4. Cribble

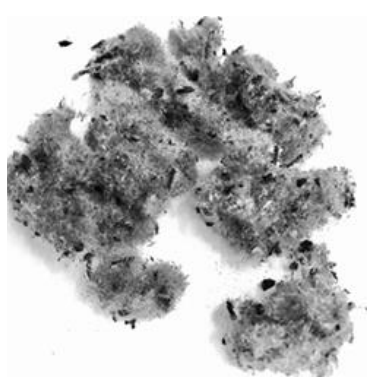

Fig. 5. Crude corde

The purifying method with the use of vibration of polyamide strings was tested and it was similar to [6]. This method proved to be the most productive. It removes more quickly large rubber particles and separates fibers significantly.

\section{Results}

The compressive and flexural strength of the mix proportions was tested according to Russian standard GOST 10180-2012. The samples were placed for 28 days in water curing tank in $20 \pm 2{ }^{\circ} \mathrm{C}$ and relative humidity of $95 \%$ until tests.

The influence of fiber content on slump and density of the concrete are presented in Figure 6 and 7.

The addition of $5 \mathrm{~kg} / \mathrm{m}^{3}$ fiber reduces up to $20 \%$ the flowability of the sand concrete mixture in comparison with the plain composition. The concrete mixture becomes more viscous due to tangled fiber.

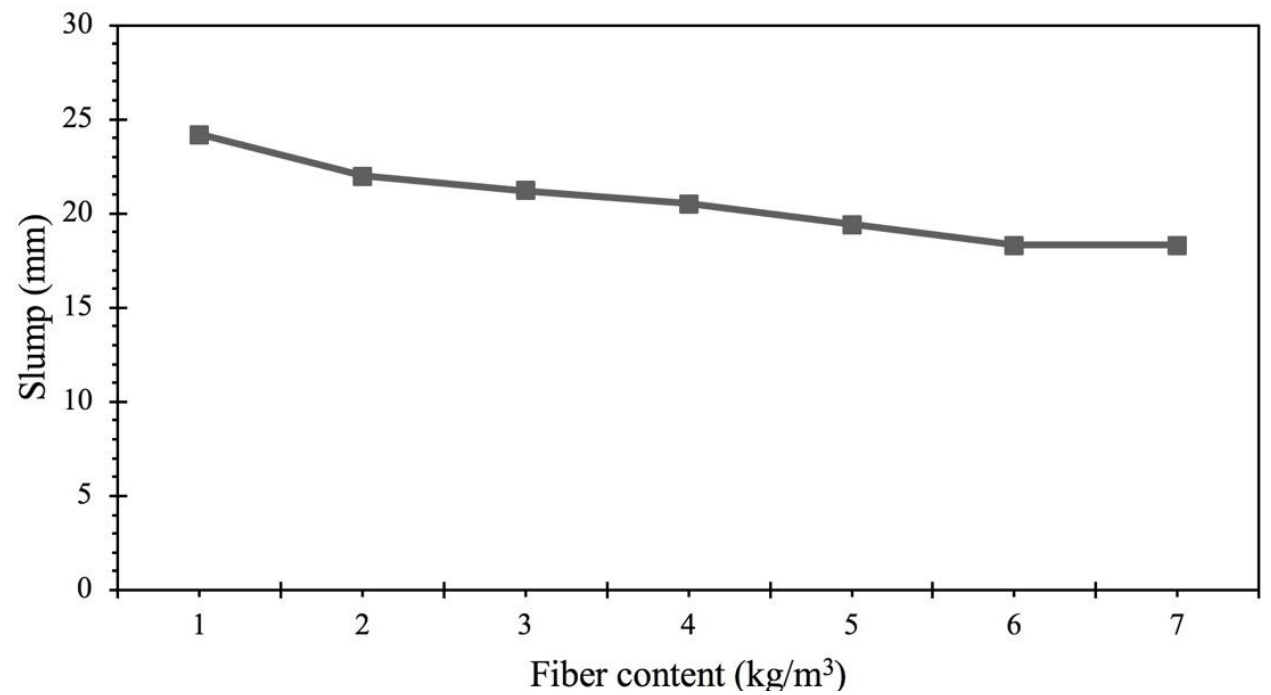

Fig. 6. The influence of fiber content on concrete mix workability.

The replacement the part of the fine aggregate by polymer fiber and rubber crumbs with small fractions explains the density reduction of the concrete mixture. 


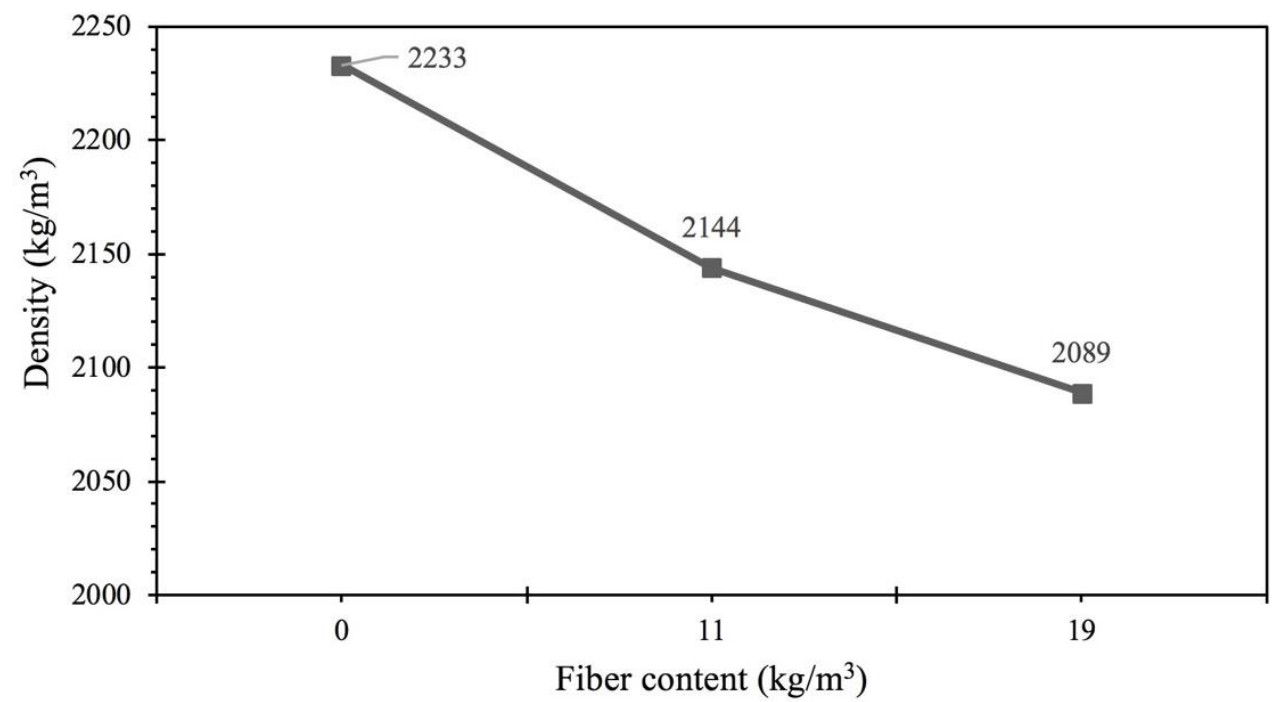

Fig. 7. The influence of fiber content on density of the concrete mixture.

The impact of $10 \mathrm{~kg} / \mathrm{m}^{3}$ fiber on compressive and flexural strength of sand concrete is presented in Figure 7. Regardless of the concrete class, the addition of fiber reduces the compressive and flexural strength compared to the plain concrete samples. The compressive and flexural strength of the concrete class B15 is reduced by $3.9 \%$ and $5.6 \%$ respectively. The compressive strength of the concrete of class B30 is reduced by $11.6 \%$, flexural strength is higher by $4.8 \%$. The compressive and flexural strength of the concrete of class B45 is reduced by $15.8 \%$ and $13.4 \%$ respectively (Fig. 8). The decrease of compressive strength can be attributed to both, the presence of higher air content and physical properties of the rubber particles $[14,15]$.

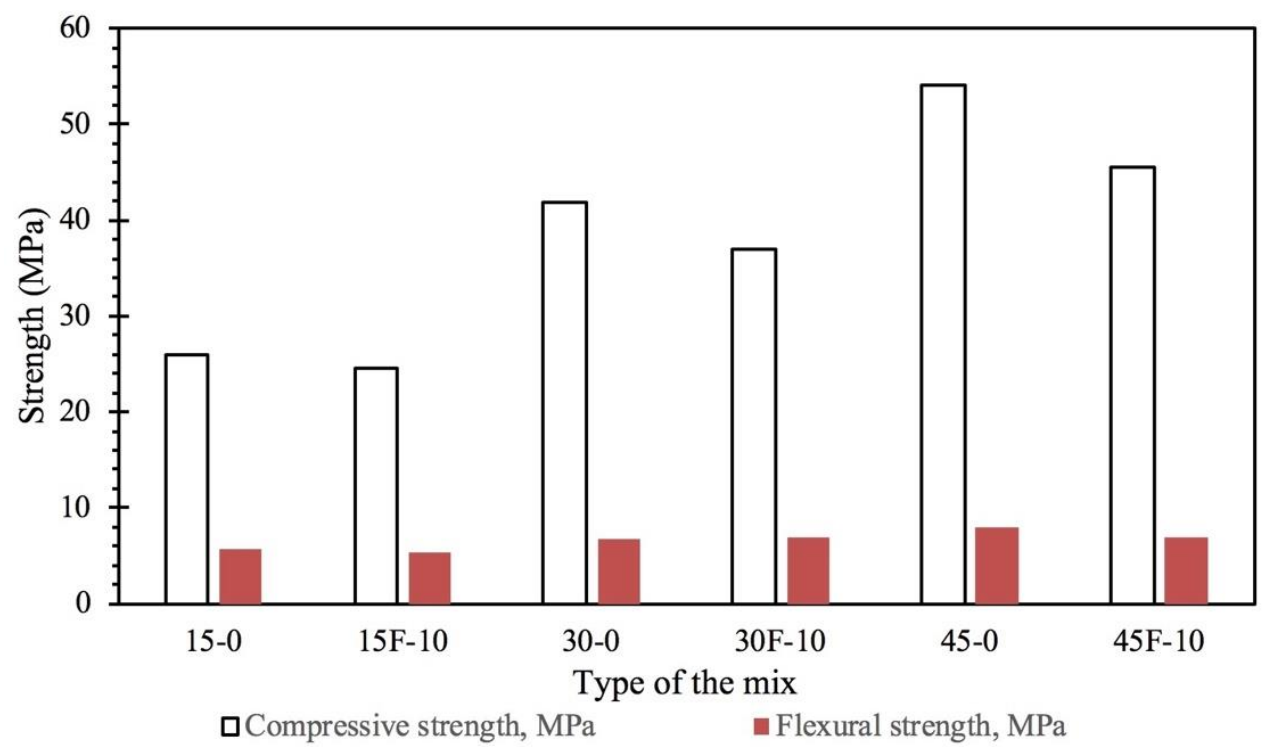

Fig. 8. The influence of fiber content on the concrete strength. 


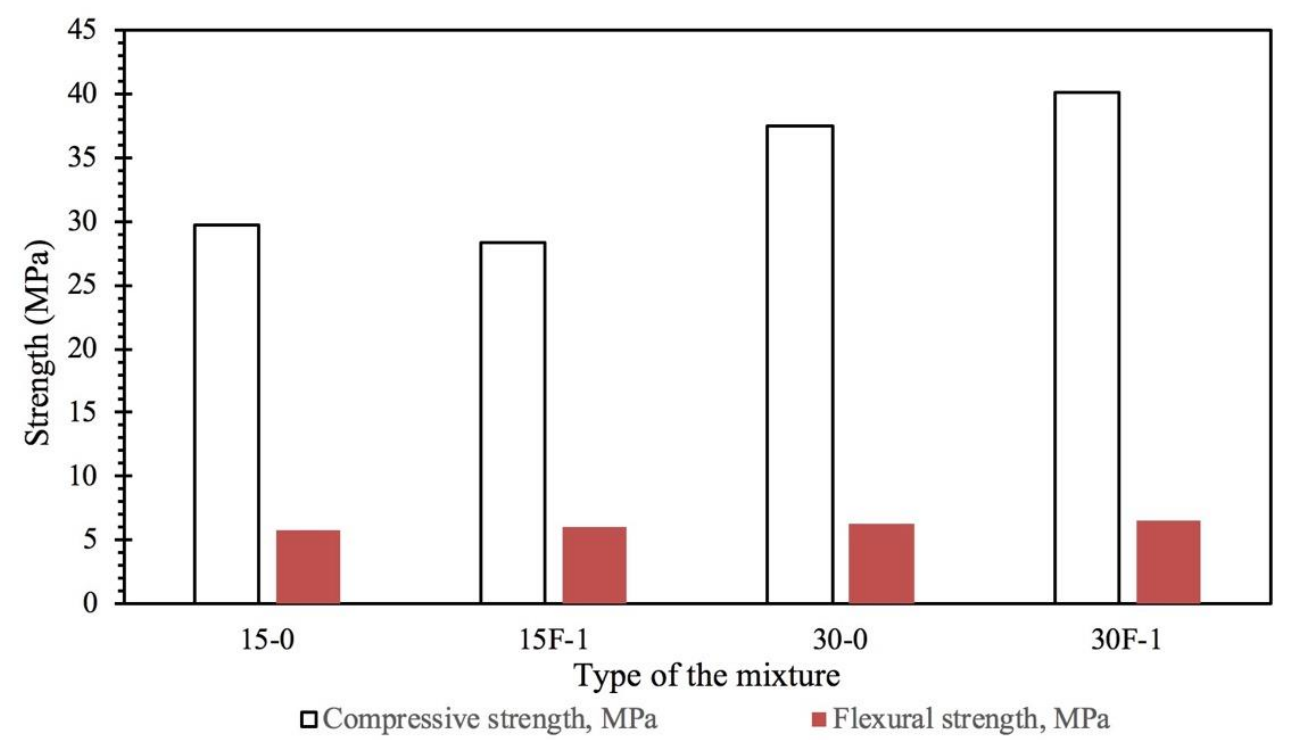

Fig. 9. The influence of fiber content on concrete strength.

The fiber content of $1 \mathrm{~kg} / \mathrm{m}^{3}$ reduces the compressive and flexural strength of concrete class B15 in $4.6 \%$ and $5.1 \%$ respectively in comparison with plain concrete samples. Concrete samples with fiber content of $1 \mathrm{~kg} / \mathrm{m}^{3}$ class B30 have lower compressive and flexural strength in $6.5 \%$ and $4 \%$ respectively.

\section{Conclusion}

The addition of fiber up to $1 \mathrm{~kg} / \mathrm{m}^{3}$ reduces the flowability of the concrete mixture up to $3.6 \%$. The addition of fiber decreases the density of the concrete mixture on $4 \%$ for each 10 $\mathrm{kg} / \mathrm{m}^{3}$.

Compressive and flexural strength of the fiber concrete samples are lower than the plain samples, regardless of the class of concrete. The adding of the fiber in the amount of 10 $\mathrm{kg} / \mathrm{m}^{3}$ of concrete class B15 reduces the compressive and flexural strength in the range of $3.9 \%$ and $5.6 \%$ respectively. The compressive strength of concrete class B 30 is reduced by $11.6 \%$, flexural strength is higher by $4.8 \%$. The compressive and flexural strength of the concrete class B 45 are reduced by $15.8 \%$ and $13.4 \%$, respectively. The compressive and flexural strength are reduced by $4.6 \%$ and $5.1 \%$ respectively of concrete class B15 with fiber content of $1 \mathrm{~kg} / \mathrm{m}^{3}$ in comparison to plain samples. The compressive and flexural strength of concrete class B 30 is higher on $6.5 \%$ and $4 \%$ respectively.

The results show that this type of fiber is more suitable of utilizing in concrete class B30. The purpose of further research is to determine the frost resistance and impact strength of sand fiber concrete.

\section{Reference}

1. Yu. M. Bazhenov, Concrete technology (ASV, Moscow, 2003)

2. F. N. Rabinovich, Composites based on dispersed reinforced concrete. Questions of theory and design, technology, construction (ASV, Moscow, 2004)

3. A. Baričević, Cem. and Concr. Comp., 91 (2018)

4. S. Mavridou, Gl. Nest J., 13 (2011) 
5. P. F. Figueiredoa, A. H. Shaha, S.-S. Huanga, H. Angelakopoulosb, K. Pilakoutasa, I. Burgess, Proc. Eng., 10 (2017)

6. A. Baričević, Cem. and Concr. Comp., 176 (2018)

7. M. Serdar, Int. J. of Pol. Sc., 9 (2015)

8. M. Chen, Cem. and Concr. Comp., 114 (2020)

9. M. Valipour, P. T. Shourijeh, A.Mohammadinia, Tr. Geot., 27 (2021)

10. O. Onuaguluchi, N. Banthia, J. of Cl. Pr., 231 (2019)

11. H. Zhong, M. Zhang, J. of Cl. Pr., 259 (2020)

12. C. Xiong, J. of Cl. Pr., 279 (2021)

13. N.F. Medina, Con. and B. Mat., 144 (2017)

14. A. Benazzouk, Cem. and Concr. Comp., 28 (2006)

15. M.A. Aiello, W. Man., 29 (2009) 